\title{
SALVADOR DE MENA (MENALIO), POESÍA Y SUMINISTROS MILITARES EN LA VALENCIA DE 1788
}

\author{
Antonio Astorgano Abajo \\ Universidad de Zaragoza
}
Para Rafael Moreno Fernández, con profundo agradecimiento

\begin{abstract}
Resumen: Salvador de Mena y Perea (Belmonte, Cuenca, 1754 - Belmonte, 1788), jurista y directivo del Banco de San Carlos (1786-1788), fue bachiller y doctor en Teología por la Universidad de Gandía (1771), aunque empezó de cero en 1773 los estudios jurídicos en Salamanca, alcanzando el bachiller y la licenciatura en Leyes. Durante la docena de años de su permanencia en Salamanca (1773-1786) fue íntimo amigo de Juan Meléndez Valdés, relacionándose con la Escuela Poética salmantina. Nuestro artículo tiene la finalidad de esbozar un retrato del personaje y su última misión: la inspección de los suministros del Ejército en Valencia (mayo-agosto de 1788).
\end{abstract}

Palabras clave: Menalio, Parnaso Salmantino, Meléndez Valdés, Banco de San Carlos, Suministros militares, Valencia, Universidad de Salamanca.

\section{Salvador de Mena (Menalio). Poetry and military supplies in Valencia in 1788}

Abstract: Salvador de Mena and Perea (Belmonte, Cuenca, 1754 - Belmonte, 1788), lawyer and director of the Bank of San Carlos (1786-1788 ), got his degree and doctórate in Theology at the University of Gandia (1771), although he began legal studies at Salamanca in 1773, reaching the degree and law degree. During the dozen years of his stay in Salamanca (1773-1786) he was a close friend of Juan Meléndez Valdés, relating to the Poetics School salmatina. Our article aims to outline its final mission: the inspection of supplies of Army in Valencia (May-August 1788).

Key words: Menalio, Parnassos Salmantino, Meléndez Valdés, Bank of San Carlos, Military supplies, Valencia, University of Salamanca.

\section{INTRODUCCIÓN' ESBOZO BIOGRÁFICO DE MENALIO (1754-1788)}

La corta vida del belmonteño Salvador María de Mena, conocido en la Historia de la Literatura con el nombre arcádico de Menalio (1754-1788), hijo del conde de Buenavista, fue estrictamente coetánea del poeta Juan Meléndez Valdés (1754-1817), cuya amistad marcará los mejores años de sus vidas en la universidad y ciudad de Salamanca (1773-1786). No fue

Data de recepció: 20 de juny de 2016 / Data d'acceptació: 28 de juliol de 2016.

${ }^{1}$ Es de justicia agradecer la inestimable ayuda del doctor don Rafael Moreno Fernández, funcionario del Banco de España e historiador del mismo, facilitándome datos del Banco Nacional de San Carlos, mucho más amplios y precisos de lo habitual entre colegas. 
poeta, ni siquiera escritor, pero tuvo su buen carácter y falta de ambición, al menos hasta 1786 en que aceptó el cargo de director bienal en el Banco Nacional de San Carlos de Madrid. Su generosa idiosincrasia y su amistad con el poeta extremeño han hecho que pasara a la historia literaria con un halo de misterio, que hemos intentado desvelar en el presente y otros artículos anteriores (Astorgano, 2016b; 2016c).

La familia lo destinó al sacerdocio, razón por la que cursó la carrera eclesiástica en el filojansenista Seminario de San Fulgencio de Murcia (1763-1769). En un progresivo, pero claro, enfriamiento y distanciamiento de su vocación eclesiástica inicial (morirá siendo "soltero"), continuará sus estudios en las mejores universidades españolas de la época. Fue bachiller y doctor en Teología por la Universidad de Gandía (1771); bachiller en Filosofía y Teología por la de Alcalá de Henares, donde también estudió Cánones y estuvo a punto de volver a doctorarse en Teología (1771-1773).

Siguió los estudios en la Universidad de Salamanca (1773-1779), donde fue consiliario (1773-1776) y diputado (1781-1785), alcanzando los grados de bachiller en leyes y cánones (1775), y la licenciatura en Leyes en febrero de 1779. Nunca quiso doctorarse en Leyes ni usar el título de doctor en teología por la Universidad de Gandía, indicio evidente de su falta de ambición, a pesar de su sólida y variada formación, y de su pertenencia al estado noble.

Una pausada lectura de los libros de claustros y juntas de la Universidad de Salamanca, nos descubre a un Mena consiliario, opositor y diputado, que, dentro de su moderación característica, siempre se alineó con el bando reformista del claustro, capitaneado los primeros años por el carmelita calzado maestro fray Bernardo Zamora, catedrático de griego, y el agustino calzado, fray Antonio José de Alba, teólogo, entonces catedrático sustituto de Humanidades, ambos maestros de Meléndez Valdés y de Mena, en cuyas clases y en las de la facultad de Derecho empezaron una amistad que durará hasta la muerte de Menalio en 1788. Discretamente, Mena siempre estuvo en el bando progresista del claustro universitario, formado por hombres calificados de tolerantistas, religiosos sin fanatismo, regalistas, filósofos y filojansenistas.

Con el presente artículo continuamos el estudio de la Escuela poética salmantina de la Ilustración, capitaneada por el poeta extremeño, esbozando la biografía de personajes menores de la misma, que empezamos con Gaspar González de Candamo (Astorgano, 2002; 2007; 2012a; 2012b).

Los pocos documentos conservados de Mena (algunas censuras de libros para el Consejo de Castilla y dos informes jurídicos para la Universidad de Salamanca) denotan poca inclinación a la ostentación y a los prejuicios sociales, a pesar de ser hijo del conde de Buenavista (Andújar Ortega, 1995, 97-103). La muerte truncó su vida a los 34 años, que parece errática en su trayectoria académica, por las varias carreras que estudió, y profesional, por el interés que mostró en acceder a la carrera docente, siguiendo estrictamente los grados y opositando infructuosamente media docena de veces a varias cátedras de Leyes, sin importarle lo más mínimo la pompa y los privilegios del grado de doctor (en esa época pura cuestión de dinero, que no era ningún problema para la familia Mena).

El currículo presentado a la oposición de Vísperas de Leyes de Toro en mayo de 1781 por el licenciado Mena y Perea ${ }^{2}$, aporta una serie de datos, que por razones de espacio sólo podemos concretar entre paréntesis sin mayor comentario:

2 AHN, Consejos, leg. 6014, exp. 91, pp. 17-18. 
Consta que tiene 19 años [1763-1781] de estudios mayores en las facultades de filosofía, teología, derecho civil, canónico y patrio.

[Estudios en el seminario conciliar de San Fulgencio de Murcia, 1763-1770].

Que estudió tres años de filosofía [1763-1766] defendiendo en los primeros conclusiones públicas de la asignatura de cada uno de ellos, y al fin del tercero un acto de las cuatro partes de esta facultad. Que asimismo estudió cuatro años de teología [1766-1770] y sustentó dos actos, y en ellos los cuatro sentenciarios. Que estuvo por espacio de seis [1763-1770] años en el seminario conciliar de San Fulgencio de Cuenca [sic, Murcia], en donde al fin de cada año fue examinado y obtuvo siempre la censura de excelente. Que en él defendió varias conclusiones públicas y leyó de oposición una vez en filosofía y dos en teología. Que hizo oposición y obtuvo una vicepresidencia de teología en la Academia de San Ginés de aquella ciudad, e igualmente una presidencia en la de Santa Quiteria [ambas de Murcia; García Hourcade, 2007, 101-114].

[Grados de bachiller y doctor en la Universidad de Gandía, abril de 1771].

Que recibió los grados de bachiller [8 de abril de 1771] y doctor [11 de abril de 1771] en Teología en la Universidad de Gandía ${ }^{3}$, precediendo el examen con arreglo a lo dispuesto posteriormente por su majestad, y fue aprobado némine discrepante. Que presidió un acto de Trinitate, Incarnatione, Peccatis et Gratia.

[Estudios y grados en la Universidad de Alcalá, 1771-1773].

Que recibió el grado de bachiller en Filosofía en la Universidad de Alcalá, y fue aprobado némine discrepante. Que igualmente recibió el de bachiller en Teología y fue también aprobado némine discrepante. Que tuvo el acto que llaman de tentativa para el grado de doctor [en Teología] en dicha Universidad, y fue aprobado némine discrepante por el claustro pleno de la facultad. Que fue sustituto de la cátedra de Vísperas de Escoto ${ }^{4}$.

[Estudios en la Universidad de Salamanca, 1773-1779]'.

Que estudió cuatro años de leyes [1775-1779] y recibió en esta Universidad [de Salamanca] el grado de bachiller [en Leyes el 5 de octubre de 1775], habiendo sido aprobado némine discrepante. Que estudió dos años de derecho canónico [1773-1775] y recibió igualmente el grado de bachiller [en cánones el 16 de octubre de 1775], siendo aprobado némine discrepante. Que tuvo dos actos pro Universitate en cánones y uno en leyes. Que presidió un acto mayor sobre el origen de la potestad de castigar, sus límites, así de la civil como de la eclesiástica, y de la independencia de los príncipes en lo temporal. Que asistió tres cursos a las cátedras de derecho real [1775-1778], y explicó cuatro años de extraordinario [1775-1779] las materias que se le señalaron. Que asistió dos cursos a la cátedra de griego con aprovechamiento [muy probablemente los cursos 1773-75]. Que fue consiliario de su nación [noviembre 1773-marzo 1776]. Que repitió para el grado de licenciado con hora y media de lección, e igual tiempo de argumentos. Que practicó los demás ejercicios acostumbrados para el grado de licenciado de esta Universidad, que recibió en 9 de febrero de 1779, siendo aprobado némine discrepante. Que fue sustituto de una de las cátedras de Instituciones Civiles y de la de Colecciones Canónicas.

[Mena, opositor a cátedras de Leyes de la Universidad de Salamanca, 1779-1782].

${ }^{3}$ Archivo Histórico Municipal de Valencia, Sección Universidad de Gandía, libro g-7, f. 168. Año de 1771.

${ }^{4}$ Además estudió dos cursos de cánones en Alcalá y asistió a la respectiva academia. AUSA, leg. 3871, exp. 27, f. 2. Expediente académico de Salvador María de Mena; AHN, Universidades, libro 558, f. 162r; AHN, Universidades, libro 560, f. 19r.

5 AUSA, leg. 3871, exp. 27. 
Que ha hecho oposición a cuatro cátedras de esta Universidad, a saber: a una de Instituciones Civiles [1779 y 1780] ${ }^{6}$, a otra de Digesto [1780] ${ }^{7}$, y a la de Derecho Público [o de Volumen, 1780$]^{8}$, y a la presente vacante de Leyes de Toro hora y media [1781].

[Mena, abogado, 1780-1786].

Es actual diputado de esta Universidad [de Salamanca, abril 1781-abril 1785] y abogado de los Caballeros 24 de la real cárcel de esta ciudad [Ayuntamiento de Salamanca] ${ }^{9}$.

No soplaban buenos aires en la Facultad de Leyes para la minoría reformista (Ramón de Salas, Juan Meléndez Valdés, Salvador María de Mena, Carlos López Altamirano...), cuyos miembros desilusionados terminarán abandonando la Universidad. Los cuatro años en que Mena fue opositor a media docena de cátedras (1779-1782) cada vez iba siendo peor informado por los jueces de los concursos, dominados por catedráticos que progresivamente se iban tornando más contrarios, conforme los jóvenes reformistas manifestaban más claramente su talante y amenazaban con ocupar alguna cátedra, a pesar del aliento de Campomanes y de algunos (muy pocos) consejeros de Castilla.

\section{MENA, DIRECTIVO EN MADRID DEL BANCO NACIONAL DE SAN CARLOS (DICIEMBRE DE 1786-DICIEMBRE DE 1788)}

Salvador de Mena ocupa el puesto de director bienal en el Banco durante catorce meses (diciembre 1786-marzo de 1788) y nueve el de director de provisiones (marzo-diciembre de 1788). Según la búsqueda realizada en el Archivo del Banco de España (ABE), no existe catalogada información alguna específica relativa a Mena. En otro sentido, carecemos de un expediente de personal del mismo. Así las cosas la única fuente de información utilizable es la que proporcionan las actas de los órganos de gobierno.

Hay indicios de que Mena pasaba largas temporadas en la Corte desde que terminó la licenciatura en Leyes en 1779, como demuestra el episodio de la última oposición a cátedras de la Universidad de Salamanca (la de Instituciones Civiles de 1782), cuando su amigo el rector Carlos López Altamirano firmó irregularmente por él dicha oposición con sonora protesta de algunos de los coopositores. No sabemos con exactitud cuándo Mena se instala definitivamente en Madrid, sirviendo el empleo de "director bienal" del Banco Nacional de San Carlos. Con toda seguridad a lo largo del otoño de 1786, pues fue elegido el 20 de

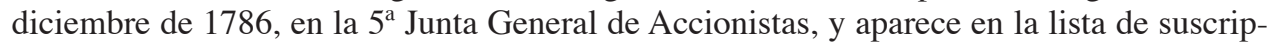
tores que encabeza el tomo II del Diario curioso, erudito, económico y comercial, correspondiente al último trimestre de 1786, junto a "los señores directores del Banco Nacional, por dos ejemplares". Lógicamente la mayoría de los 800 suscriptores mal contados, encabezados por el rey, son nobles, funcionarios e intelectuales residentes en la Corte, como Eugenio de Llaguno, Estanislao de Lugo o el conde de Montijo, brillando por su ausencia los salmantinos ${ }^{10}$.

${ }^{6}$ AHN, Consejos, leg. 6010, exp. 93. Mena opositó tres veces a la cátedra de Instituciones Civiles, que era la de entrada en la carrera docente en la facultad de Leyes.

7 AHN, Consejos, leg. 6012, exp. 135.

8 AHN, Consejos, leg. 6012, exp. 121.

9 AHN, Consejos, leg. 6014, exp. 91, 17-18.

10 Diario curioso, erudito, económico y comercial, tomo II (octubre, noviembre y diciembre de 1786), Madrid, Imprenta de Manuel González. Lista de suscriptores en pp. 1-8. 


\subsection{El Banco Nacional de San Carlos que gestionó Mena}

Menalio llega al Banco de San Carlos cuando iniciaba su crisis y frenaba su expansión, y cuando Floridablanca deseaba incrementar el peso de los abogados en su gestión, para ejercer, además de sus funciones propias, la de control, es decir, actuarían como comisarios encargados de tareas revisoras del balance. Además, en 1788 se designó una comisión formada por accionistas para calificar el comportamiento seguido por los directores anteriores, mayoritariamente políticos y comerciantes. Finalmente, un cúmulo de circunstancias y acontecimientos, conduciría en 1790 a la salida de la institución de la primera dirección y al encarcelamiento de Cabarrús (Moreno Fernández, 2009, 7-8). No sabríamos precisar si Mena debió su cargo al patrocinio de Floridablanca, del ya controvertido Cabarrús o de Campomanes, si bien nos inclinamos por el patronazgo de este último, dada la manifiesta protección del fiscal asturiano sobre el poeta Meléndez y sobre Gaspar González de Candamo, los dos íntimos amigos del manchego. Para comprender la posición de Mena en el organigrama del Banco de San Carlos, recordemos que estaba configurado por las Juntas Generales de Accionistas, Junta de Dirección, Dirección de Giro, Dirección de Provisiones, Teneduría General, Caja y Secretaría.

Mena tiene que gestionar una organización financiera que en cinco años se había convertido en un organismo de más de 400 funcionarios, un auténtico monstruo en la débil estructura del Estado de la época. Inicialmente había ocho directores, nombrados por los accionistas: seis bienales y dos de Provisiones. Al año siguiente al de la formación del Banco, se crearon dos plazas de directores de Giro, con salario igual al de los de Provisiones. En 1785 pasa a ser director de Provisiones el marqués de las Hormazas, enemigo solapado de Cabarrús, que dimitiría dos años después, de modo, que solo quedó Juan Bautista Rossi hasta que se añadió Salvador de Mena en marzo de 1788. De los 21 directores con que contó el Banco entre 1783 y 1790 (Tedde, 1988, 167), observamos que solo cinco de ellos permanecieron un lustro o más (Moreno Fernández, 2014, 52). Por los distintos curricula de Menalio, sabemos que su experiencia financiera o comercial era casi nula. Pero el resto de los directores bienales, excepto los que pasaron a ser directores dotados -Juan Bautista Rossi, Pedro Bernardo Casamayor, el marqués de las Hormazas-, tampoco debía contar con gran pericia en asuntos mercantiles o bancarios.

Había dos directores de Provisiones del Banco de San Carlos, y cuando el 2 de abril de 1789 se debatió el nombramiento del sustituto del fallecido Mena, "la Junta consideró que las circunstancias del Banco le imponen la más severa economía", por lo que "se oyó con aplauso la extinción de la plaza de director de provisiones que había recaído en el señor Mena" (BNSC, 1789, 121). El abogado belmonteño se había integrado en poco tiempo en el Cuerpo de la Dirección del Banco, en el que confluían los directores bienales, los directores de Giro y de Provisiones, además de los directores natos, aunque sobre estos se precisa que puede nombrarlos la Junta General de Accionistas, mas no debería multiplicarse ese honor, reservándose para los mayores servicios ${ }^{11}$. Al estar próximo que el Banco dejara de ocuparse de las provisiones (por presiones de otros asentistas, como los Cinco

11 BNSC, Reglamento de la Junta de Gobierno de 1789 (RJGA1789), artículo 40. ${ }^{\circ}, 30$. 
Gremios Mayores), queda previsto que, cuando sus plazas se supriman, aumentará el número de los directores bienales, con dos sujetos instruidos en el comercio, prefiriéndose los que tuvieran conocimientos de los asuntos del Banco ${ }^{12}$.

\subsection{Mena director bienal (diciembre de 1786-marzo de 1788)}

El 18 de diciembre de 1786, en la propuesta de la Dirección para reemplazar a Francisco Xavier Larumbe, que finalizaba su ejercicio, se señalan, en el orden de nobleza, como candidatos a la terna formada por Salvador María de Mena, Valentín Foronda y Manuel Santamaría (BNSC, 1787, 124-125). Saldría elegido, a pluralidad de votos, el primero de los mencionados. Con el nombramiento de la Junta General, un par de días después, la Junta de Dirección del 20 de diciembre, al conocer que Salvador María de Mena aceptaba el empleo de director bienal honorario, acuerda que se le dé el asiento que le correspondía en señal de posesión ${ }^{13}$.

Durante el año 1787 no encontramos referencias específicas en las actas relacionadas con Mena. Sin embargo, a principios de enero de 1788, se toma el acuerdo de que Salvador de Mena sustituya en el semestre al marqués de Astorga-conde de Altamira (director nato, junto con Cabarrús), impedido por sus ocupaciones como caballerizo mayor del príncipe $^{14}$. Por consiguiente, nada especialmente destacable debía hacer Mena como director bienal, más que estudiar los temas sometidos a las reuniones y acudir a estas cuando lo convocaban. Mena abandona el cargo de director bienal el 1 de marzo de 1788, cuando en el transcurso de la $6^{\mathrm{a}}$ Junta General de Accionistas fue propuesto para director de Provisiones (Tedde, 1988).

\subsection{Problemas de gestión del Banco Nacional de San Carlos en tiempos del director Mena (1786-1788)}

Salvador Mena se codeaba con la élite dirigente político-financiera del reinado de Carlos III, pues, por ejemplo, el conde de Revillagigedo dimitió de su puesto de director bienal del Banco de San Carlos porque había sido nombrado virrey de Nueva España. Menalio llega a un Banco de San Carlos, cuando, pasados los tres o cuatro años primeros, de bonanza (1782-1785), empezaban a surgir críticas sobre la gestión del mismo, ya fueran por arriesgadas operaciones, o infundadas en la lucha por el poder. Resumiendo, Mena es director del Banco de San Carlos, primero bienal y después de provisiones, cuando las relaciones entre su director, Cabarrús, y el ministro de Hacienda, conde de Lerena (Valdemoro, 30 de abril de 1734 - 2 de enero de 1792), eran bastante tirantes, tanto que en 1790, ya fallecido Menalio, darán con los huesos del financiero francés en la cárcel, a pesar de los esfuerzos de Jovellanos por evitarlo.

En concreto, Mena se vio afectado de lleno por la quiebra de Juan Bautista Montaldi, un acreditado del Banco de San Carlos que dejaba a deber, según un documento interno,

\footnotetext{
12 BNSC, RJGA1789, artículo 47. ㅇ, 33.

13 ABE, Secretaría, AJD (20.12.1786), libro 139, f. 1.

14 ABE, Secretaría, AJD (5.1.1788), libro 140, ff. 310-311.
} 
1.775.985 reales con 28 maravedíes en letras giradas a obligados totalmente insolventes o en quiebra ${ }^{15}$. Era el punto de partida de la desconfianza en la gestión de la Dirección del Banco, acusada de haber dado trato de favor hacia un cliente con el que no se debía haber seguido operando, pero al mismo tiempo sacaba a la luz la actuación de los directores del establecimiento, que también operaban como comerciantes con el Banco, en una posible dinámica de auto concederse operaciones ${ }^{16}$. Debían estar circulando ciertos rumores y críticas contra la Dirección. Por ello, en la Junta de Dirección de 22 de octubre de 1787 plantean dirigir una representación al Rey, expresando que el quebranto por la quiebra de Montaldi sería, a lo sumo, de seis reales y medio por acción, a deducir del dividendo a repartir $^{17}$. Su objetivo era que el monarca les diera audiencia para explicar directamente su comportamiento, recalcando que era la única pérdida acaecida de esa clase desde la fundación del Banco, la cual debería reputarse por leve, si se comparaba con el descrédito que resultaría de cualquier examen o innovación en su Instituto.

Sin embargo, el conde de Floridablanca no sólo suspende la entrega de dicha representación dirigida al rey, sino que, además, les pide explicaciones por medio de la Real Orden de 25 de octubre de $1787^{18}$. En tal disposición el monarca expresa su deseo de saber la verdad acerca de por qué se tomaron las letras con la sola firma de Montaldi -y no con las tres obligadas por la Real Cédula de erección-, así como la responsabilidad de los directores del Banco que las tomaron.

A raíz de este suceso se iniciará un cierto cambio de actitud gubernamental sobre el comportamiento de la Dirección del establecimiento, si bien en ese momento no se trasluce gran desconfianza contra los directivos. Mes y medio después, el 13 de diciembre de 1787, el Banco da contestación a la citada Real Orden de 25 de octubre, rechazando la insinuación de que hubiera querido ocultar el descubierto de la quiebra de Montaldi ${ }^{19}$.

En 1787 el dividendo anual había disminuido y la posición del establecimiento se vio alterada con la citada quiebra, lo que, unido a la disminución de beneficios del año anterior, hizo que todos los males se atribuyeran a los que administraban el Banco, incluido Salvador María de Mena, más que a los riesgos o defectos que pudiera presentar per se la Institución. Para acallar las críticas y los recelos de Floridablanca, la Junta de Dirección propuso en la sexta Junta General de accionistas (24 de febrero de 1788) la formación de una comisión, compuesta por tres magistrados, tres comerciantes y tres miembros sin distinción de clase. En ella se escucharía a los directores del Banco y dependientes, y se revisarían los documentos necesarios. Su actuación estaba destinada a acallar los rumores públicos sobre el comportamiento de los directores ${ }^{20}$.

Mena murió a tiempo de no verse involucrado en las acusaciones que el ministro de Hacienda, conde de Lerena, hizo contra Francisco Cabarrús, cuyos problemas más serios tuvieron formalmente su origen en la representación acordada y aprobada por unanimidad en las primeras sesiones de la Junta General de Accionistas de 1790, en la cual se solicita de nuevo

15 ABE, Secretaría, leg. 786.

16 ABE, Secretaría, leg. 786.

17 ABE, Secretaría, caja 1072; ABE, Secretaría, AJD (22.10.1787), libro 156 -AR-, ff. 127v y ss. (Moreno Fernández, 2014, 79-80).

18 ABE, Secretaría, AJD, libro 156, día 27.10.1787; Actas reservadas (AR), f. 130.

19 ABE, Secretaría, caja 1072 (Moreno Fernández, 2014, 30-31).

20 ABE, Secretaría, caja 1072 (Moreno Fernández, 2014, 37). 
de la justicia del Rey el reembolso de los intereses y las pérdidas experimentadas en las provisiones. El informe dado por Lerena al monarca se reducía a impugnar la justicia de esta pretensión, al suponer abusos y desordenes ocultos en la Dirección del Banco ${ }^{21}$.

\section{MENA DIRECTOR DE PROVISIONES (MARZO-DICIEMBRE DE 1788)}

Para contextualizar la gestión de Mena como director general de Provisiones del Banco de San Carlos, debemos remitir a varios estudios de Zylberberg (2004), de Rafael Torres Sánchez (2002a, 2002b, 2003, 2008, 2012, 2013), de González Enciso (2012) y de Solbes Ferri (2015). A lo largo del siglo XVIII, el fracaso o el desabastecimiento en el suministro al Ejército fue el motor de cambio de método de aprovisionamiento, lo que justifica la alternancia entre el asiento y la gestión directa por parte del Estado. Como regla general, cuando había dificultades o el negocio no interesaba a los asentistas (guerras, malos años agrícolas...), el Estado tenía que asumir la gestión directa. Durante la guerra contra Gran Bretaña, 1779-1783, los Cinco Gremios Mayores se mostraron incapaces de atender la escalada de exigencias de préstamos y crédito del gobierno, lo cual propició la entrada del Banco de San Carlos en el negocio de los asientos (actividad bastante extraña a la naturaleza de un instituto bancario). Aunque había muchos asentistas, en la práctica, los Cinco Gremios Mayores de Madrid actuaron durante muchos años como oligopolio, solo disputado durante unos años (1784-1789) por el Banco Nacional de San Carlos, que actuó como asentista oligárquico bajo la dirección de Cabarrús. Por lo tanto, Salvador de Mena fue directivo del Banco en esa etapa, poco antes de caer en desgracia el banquero francés, acosado por los asentistas españoles, encabezados por los Cinco Gremios Mayores. Ante los problemas que tenía el Banco de San Carlos para cumplir su suministro de víveres por asiento, el secretario de Hacienda, Pedro López de Lerena, ordenó cambiar de método "porque si no se rescinde este asiento vendrá a arruinar a los accionistas [del Banco], sin cuya noticia e intervención se hizo", y se ajustó con los Cinco Gremios Mayores para que hiciesen este suministro, explícitamente, "por administración"22. Para el Estado parece que la prioridad era que la tropa tuviese su suministro, y con ello estuviese operativa, y el método podía quedar en un segundo plano (Torres Sánchez, 2013, 171-172).

Solbes Ferri (2015), refiriéndose a la provisión de uniformes para el ejército, observa que el Estado español recurrió permanentemente a los hombres de negocios para la provisión de los ejércitos y siempre contó con agentes privados en su papel de intermediarios (tanto el Banco de San Carlos como los Cinco Gremios Mayores son, en esencia, organismos privados), pero nunca con el propósito de utilizar el gasto miliar para fomentar el incremento de la producción nacional en el largo plazo. Se aprecia un proceso de concentración monopolística obsesivo que finalmente sitúa la provisión en manos de unos pocos asentistas, seleccionados por el secretario de Hacienda como medio para intervenir e influir en sus actividades. Este modelo alcanza el paroxismo en los años 1780-90 con la entrada en el negocio de organismos como el Banco de San Carlos y los Cinco Gremios Ma-

\footnotetext{
21 ABE, Secretaría, caja 1072 (Moreno Fernández, 2014, 93-94).

22 AGS, SSH, leg. 647. Resolución de Pedro de Lerena del 3-9-1789 (Torres Sánchez, 2012, 407-432 y 430).
} 
yores. La cuestión del gasto militar y los mecanismos de la provisión del ejército constituyen un mundo muy complejo en el que se inmiscuyen corporaciones gremiales, fábricas reales, fábricas privilegiadas, productores e intermediarios privados con instituciones públicas de control, lo que hacía muy complicado el empleo que asumía Mena.

El abogado belmonteño gestiona los suministros cuando el Banco ya estaba perdiendo la batalla en su enfrentamiento con los anteriores asentistas, que con los Cinco Gremios Mayores al frente, el apoyo del tesorero general Francisco Montes y el beneplácito del secretario de Hacienda, Pedro Lerena, lograrán en pocos años desacreditarlo y expulsarlo de todos sus negocios. El Banco tenía el enemigo en casa, pues el marqués de Hormazas (antiguo asentista de víveres de la Armada), a quien sustituirá Mena en la dirección de suministros, era un decidido partidario de que todos los asientos volvieran a ser concedidos a asentistas españoles, expulsando a los extranjeros (Cabarrús y su criatura, el Banco de San Carlos). El triunfo de Cabarrús en los suministros militares apenas duró 5 años y la causa de su fracaso fue la oposición de los españoles (Torres Sánchez, 2013, 183-184).

Una creciente oposición de las élites económicas y políticas del país hacia los negocios de Cabarrús, entre las que destacó la de los propios Cinco Gremios Mayores (Sánchez Torres, 2008, 103-120), unida a la mala gestión realizada por el Banco en el asiento del suministro, logró que en 1788 Cabarrús cayera en desgracia, y, significativamente, que de forma específica fuese retirada de las funciones del Banco la gestión de la provisión de víveres. Los "negocios" de Cabarrús, y su interés por el abastecimiento al ejército, duraron menos de 7 años. Fue un pequeño bache en el dominio establecido por los Gremios. En 1790, el gobierno volvió a conceder a los Cinco Gremios el asiento de víveres al ejército. De nuevo, eran la opción segura. A juicio de Torres Sánchez (2013, 183184), la rápida y fulgurante caída de Cabarrús nos habla, no tanto de la influencia francesa, como de la capacidad alcanzada por los hombres de negocios españoles para defenderse de la entrada extranjera.

Sabemos por la Memoria del Banco de San Carlos, leída en la $5^{\mathrm{a}}$ Junta General de Accionistas del 18 de diciembre de 1786, que el director de Provisiones Juan de Piña, teniendo como secretario a Juan Bautista de Ceán Bermúdez (que había sido secretario de Jovellanos, luego de Cabarrús y que será célebre historiador del Arte), realizó una inspección o visita de tres meses y diez días (entre el 24 de julio de 1786 y el 3 de noviembre de ese año), con el objeto de averiguar en Andalucía, Murcia y Extremadura las posibles economías en las provisiones de víveres del Ejército y Corte, así como las existencias que debían tener las comisiones y factorías, revisando o realizando nuevas contratas, de lo cual se da cuenta en la Memoria (BNSC, 1787). Esa visita será continuada, con el mismo secretario Ceán Bermúdez, por el nuevo director de Provisiones Salvador María Mena (mayo-agosto de 1788) (Moreno Fernández, 2009, 108).

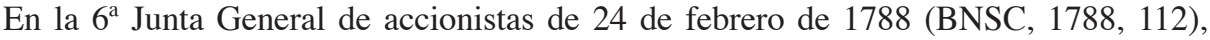
para reemplazar una de las dos plazas de director de provisiones -que se encontraban vacantes por dimisión de Juan Joseph de Goicoechea y del Marqués de las Hormazas-, la Dirección va a proponer a Francisco Xavier de Larumbe, Juan de Piña y Ruiz, Salvador de Mena y Ramón Talavera y Dalmaces. La Junta General elige, a pluralidad de votos, a Francisco Xavier de Larumbe y a Salvador de Mena, para que, finalmente, el Rey escogiera el que fuera de su agrado (BNSC, 1788, 177-178). Habiendo cuatro candidatos, dicha Junta seleccionó a dos, que, propuestos al rey, éste designó a Mena. Por lo tanto, el belmonteño gozaba de firmes apoyos en los ministerios afectados (Ejército y Hacienda). 
Unos días antes de tener constancia oficial de la designación del Rey, la Junta de Dirección acuerda que Salvador María de Mena, director bienal entonces, desde el día siguiente pasase a ayudar a Juan Bautista Rossi a despachar asuntos de provisiones ${ }^{23}$. Inmediatamente la Junta de Dirección encarga a los directores de provisiones que informen sobre el ramo del vestuario, que era el tema de mayor urgencia en ese momento.

Acto seguido, Pedro de Lerena (ministro de Hacienda) por Real Orden comunicada el $1^{\circ}$ de marzo al marqués de Velamazán-conde de la Coruña -como primer director del Banco- le manifiesta que el conde de Floridablanca en aquella fecha le decía que, en vista de la representación del Banco del 28 del mes anterior, el Rey se había servido nombrar a Salvador de Mena para la plaza de director de provisiones. Siguiendo el protocolo habitual, aceptando Mena esta plaza, se le dio posesión de ella, tomando el asiento que le correspondía ${ }^{24}$.

Por consiguiente, de los cuatro candidatos propuestos a la Junta General, esta escoge a dos y, finalmente, el Rey designa a Salvador de Mena para el cometido de director de provisiones. Esto supone que, a pesar de que contara con determinados apoyos (Campomanes, etc.), tuvo que pasar por los filtros de la Junta General y luego la designación real.

Mena sólo fue director general de provisiones activo durante unos cinco meses (marzo de 1788-agosto del mismo año), pues pronto enfermó. Desafortunadamente no podemos evaluar directamente su actividad como director de provisiones, porque ha desaparecido del Archivo del Banco de España la documentación de dicha dirección general.

\subsection{Designan a Mena para realizar una visita a provincias}

Como hemos dicho 1787 fue el primer año difícil desde que el Banco se inaugurase, efectivamente, en 1783. A los problemas de la gestión de las provisiones, que ya se habían suscitado con anterioridad, se unieron otros que cuestionaban la dirección de Cabarrús. Por otra parte, la actividad interna del Banco iba a estar, en cierta medida, si no vigilada sí al menos alterada por una comisión creada en la $6^{\mathrm{a}}$ Junta General y compuesta por nueve accionistas, la cual desarrollaría su actuación revisora a lo largo de 1788 y de la que se daría cuenta en la siguiente Junta General -la 7ª - Tal comisión empezaría sus trabajos el 12 de marzo de 1788, es decir apenas unos días después de la designación de Mena como director de provisiones (Moreno Fernández, 2014, 36-45). Bajo estas condiciones y condicionantes, el admitir el puesto de director de provisiones debía representar un reto y una tarea altamente compleja, que Mena, sin duda conscientemente, asumió.

En otro aspecto, la cercanía en el tiempo de las visitas realizadas hasta finales de 1786 por Juan de Piña, más el esfuerzo personal que representaba para los directores que las efectuaron, posiblemente determinasen que no se volviera a plantear su realización hasta 1788. En el caso de directores bienales -sin sueldo- suponía estar unos 3 meses alejados de sus ocupaciones habituales, de sus casas y familias.

Sea como fuere, la Junta de Dirección ahora nuevamente establecía "como útil e importante continuar con las visitas de las Direcciones y Factorías que el Banco tiene establecidas en las Provincias, especialmente en las de Valencia, Andalucía y Extremadura y

\footnotetext{
23 ABE, Secretaría, AJD (29.2.1788), libro 141, ff. 10-12.

24 ABE, Secretaría, AJD (4.3.1788), libro 141, ff. 17-18.
} 
en los departamentos"25. Para ello, nombra a Salvador María de Mena, director de provisiones, con iguales facultades que las ejecutaron anteriormente Francisco Cabarrús, Francisco Javier Larumbe y Juan de Piña Ruiz. Recordar que estos tres mencionados fueron directores que no percibían retribución alguna; por el contrario, Salvador de Mena, como director de provisiones, tenía el salario de 80.000 reales al año, lo que suponía más del triple de lo que recibirá al año siguiente su amigo Meléndez Valdés, cuando ingrese en la magistratura como alcalde del crimen en la Audiencia de Aragón (septiembre de 1789).

El objetivo principal de la visita era el hacer todos los subarriendos que fuera posible $\mathrm{y}$, en su defecto, mejorar los ajustes celebrados con los panaderos; disminuir los gastos del suministro de trigo o cebada (Torres Sánchez, 2012); enterarse del método de cuenta que tiene cada Director, Factor o Comisionado; adquirir las noticias conducentes a ilustrar a la Dirección, ya en orden a las personas que emplean, ya con respeto a los negocios que manejan y, finalmente, todas las que fueren relativas a los encargos del Giro, Presidios, Marina y Herrajes para mejorarlos. En una palabra, tratar de gestionar el Banco con la cercanía de la información "in situ".

Por otra parte, la Junta dejaba al arbitrio de Salvador María de Mena la elección del oficial que le acompañara e hiciera de secretario, así como de algún otro si lo consideraba conveniente.

Mencionar que dentro de esta misma acta, la Junta acuerda que el tenedor general de libros -Pedro Davout- forme un plan analítico por años de las pérdidas que han experimentado las provisiones y los ramos de que provengan, pues, conviene tenerlo presente para lo que se ofrezca. Era este el tema que preocupaba en la institución y marcaba la agenda de Mena.

\subsection{Mena elige como secretario que le acompañe a Ceán Bermúdez}

Menalio, a consecuencia de la facultad que la Junta de Dirección le dio para elegir el oficial que lo había de acompañar y hacer de secretario de las visitas, y llevar algún otro funcionario, si lo considerase conveniente, eligió solamente a Juan Agustín Ceán Bermúdez (Gijón, 1749-Madrid, 1829), oficial mayor de la Secretaria del Banco, basado en el conocimiento práctico que este tenía en el manejo y desempeño de esos asuntos, el cual fue adquirido en las visitas anteriores realizadas con Juan de Piña. La Junta aprobó esta elección por constarle esas circunstancias ${ }^{26}$.

Esta decisión era la esperable ya que, en la visita en la que Ceán acompañó al anterior director de provisiones Juan de Piña, éste había informado a la Junta de Dirección, del particular mérito contraído por Ceán, respecto de que había trabajado, escribiendo todo el día y gran parte de la noche, formando todos los expedientes, en lo cual tuvo el mayor cuidado y vigilancia, contribuyendo con sus luces e instrucción al acierto y desempeño de todas estas operaciones. Tanto fue así que la Junta le gratificó, por una vez, con 15.000 reales y esperaba que "por la repetición de los mismos u otros méritos se haga acreedor a mayor premio" 27 . Por consiguiente, Ceán Bermúdez de esta forma casi quedaba designado

\footnotetext{
25 ABE, Secretaría, AJD (3.4.1788), libro 141, ff. 108-109.

26 ABE, Secretaría, AJD (14.4.1788), libro 141, ff. 142-143.

7 ABE, Secretaría, AJD (23.11.1786), libro 138, ff. 269-269v.
} 
y destinado a repetir en esos cometidos, caso de que se realizasen nuevas visitas en el futuro. Además, la visita de Piña había sido efectuada, prácticamente, a los mismos destinos que ahora se programaban. En estas condiciones, la presencia de Ceán Bermúdez constituía más que una valiosísima aportación por su conocimiento y experiencia ${ }^{28}$.

\subsection{Preparación de la visita (abril-mayo de 1788)}

En tanto que Mena inicia la visita, hace el trabajo propio de director de Provisiones en Madrid entre el 3 de abril y el 26 de mayo. Por ejemplo, se encarga de elaborar las correspondientes representaciones motivadas por el ramo de vestuario que le encomienda la Junta de Dirección ${ }^{29}$.

Además, pendientes de la visita que había realizado Juan de Piña en 1786, quedaban cuestiones que debían resolverse. Una de ellas era la reunión, en un solo punto, de diferentes almacenes y fábricas de galletas y pan de munición de Cartagena. Una vez realizada la obra por el maestro de albañilería Juan Martínez, el Banco entrega a Salvador de Mena el informe, memorial, plan y presupuesto de esa obra para que, cuando llegase a Cartagena, satisficiera al citado maestro lo que correspondiera legítimamente por su trabajo ${ }^{30}$.

En igual sentido, en la Junta de Dirección se comenta la carta del director del Banco en Cartagena en relación con la cobertura de la vacante de contador en Orán y la plaza de maestre de buques desarmados ${ }^{31}$. De ello y de otras cuestiones relacionadas con el personal se le da aviso a Salvador de Mena para que lo trate allí mismo ${ }^{32}$.

Por otro lado, la Junta va a recabar la colaboración de los Intendentes de Valencia, Murcia, Andalucía y Extremadura, y de los jefes de los departamentos de Cádiz y Cartagena para que auxilien a Salvador de Mena en las visitas a la provisión de víveres del Ejército y la Armada, suplicando a los ministros Pedro de Lerena y Antonio Valdés se sirvan expedir las órdenes oportunas, similares a las que se emitieron en 13 de junio de 1786, cuando se hicieron iguales visitas ${ }^{33}$. Las citadas órdenes llegan al Banco por oficio de Pedro de Lerena de 19 de mayo, dirigido al primer director -marqués de Velamazán-, acordando la Junta de Dirección que se remitan a Salvador de Mena, para su gobierno ${ }^{34}$.

Quedaba ya todo dispuesto para que Menalio pudiera partir, siendo la fecha de esta última Junta de Dirección de 26 de mayo la que viene a indicar que su salud, en ese momento, no debía presentar problema alguno ya que, en otro caso, se hubiera pospuesto la salida.

La visita de Mena empezaba prácticamente en el mes de junio, en tanto que la de Juan de Piña había comenzado en su día casi dos meses más tarde, al ser practicada entre el 24 de

${ }^{28}$ Ceán había entrado cuando la apertura del Banco - marzo 1783- prestando sus servicios en la Teneduría General de Libros como oficial segundo y, en ese momento -mayo 1788-, era oficial de la Secretaría, como se ha indicado (Moreno Fernández, 2009, 39-41).

29 ABE, Secretaría, AJD (19.4.1788), libro 141, ff. 153-156.

30 ABE, Secretaría, AJD (10.5.1788), libro 141, ff. 244-246.

31 Orán, ciudad al norte de Argelia, por entonces bajo soberanía española, si bien en pocos años se perdería.

32 ABE, Secretaría, AJD (26.5.1788), libro 141, ff. 345-346.

33 ABE, Secretaría, AJD (14.5.1788), libro 141, ff. 313-315.

34 ABE, Secretaría, AJD (26.5.1788), libro 141, f. 340. 
julio de 1786 y el 3 de noviembre de ese año (Moreno Fernández, 2009, 108). Las condiciones de calor, en los meses centrales de verano, podrían tener importancia para explicar la misteriosa última enfermedad de Menalio.

\subsection{Desarrollo de la visita en Valencia (principios de junio-principios de agosto de 1788): problemas de salud}

Previsiblemente, Mena inicia la visita saliendo de Madrid después del 26 de mayo y antes del 31 del mismo mes, y enferma en esos días durante el viaje a Valencia (probablemente los días 28 o 29). Aun así, alcanza su primer destino en Valencia el 31 de mayo. Pone fin a la visita a Valencia, por su enfermedad, presumiblemente, el 5 de agosto y, sintiéndose gravemente enfermo, se dirige a su nativa Belmonte, donde ya se encuentra el 24 de agosto. Desconocemos más datos sobre los casi cuatro meses que permaneció con su familia, hasta que su padre comunica a la dirección del Banco su fallecimiento el 8 de diciembre, a mediados de dicho mes.

Es en la sesión de 31 de mayo, es decir apenas 5 días después de la última Junta de Dirección comentada, cuando en las actas se hace constar que la Junta ha sabido que Salvador de Mena continúa sin mejoría en su quebrantada salud ${ }^{35}$. En consecuencia, la enfermedad se le ocasionó en el transcurso del inicio del viaje. A la vista de esta circunstancia, la Junta reconoce que Mena no puede atravesar sin peligro la Andalucía y Extremadura, con los calores de los meses de julio y agosto, y acuerda que se le escriba para que suspenda por ahora su visita, recomendándole detenerse en Valencia o venir a su casa de Belmonte o a la Corte, hasta restablecerse enteramente, y que pudiera seguir entonces dicha visita sin ningún riesgo. Se acuerda que este aviso se dirija a Ceán Bermúdez, para que lo ponga en manos de Mena, caso de que no hubiera conseguido en aquella ciudad el alivio y mejoría que necesita para continuar esta comisión sin peligro de su vida.

A pesar de esas complicaciones, Menalio, en oficio de 3 de junio, indica haber llegado a Valencia el 31 de mayo y que había dado principio a su comisión, realizando algunas diligencias para intentar conseguir el subarriendo de la provisión de víveres. También había solicitado al Intendente la relación certificada de los precios (el más alto y el más bajo) que han tenido los trigos en cada mes, trimestre o cuatrimestre, desde los años 1778 hasta el presente. Estos primeros pasos le parecieron bien a la Junta de Dirección y acordó que así se le manifestase ${ }^{36}$. Por otro oficio, Salvador de Mena hacía determinadas observaciones respecto al encargo que se le había requerido en Cartagena, para cubrir las vacantes y las cuestiones relacionadas con el personal, que la Junta tomaba en consideración de cara a su cumplimiento ${ }^{37}$. En estos oficios Salvador de Mena no hace ninguna alusión a su salud, poniendo claramente por delante la tarea que se le ha encomendado, la cual inicia con total actividad y dedicación.

Unos 10 días después, en un oficio de 14 de junio, Salvador de Mena agradece a la Junta el acuerdo comentado del 31 de mayo. Indica que tiene alguna mejoría desde que empezó a tomar baños de agua de mar, y las esperanzas que mantiene de recuperarse con

\footnotetext{
35 ABE, Secretaría, AJD (31.5.1788), libro 141, f. 374.

6 ABE, Secretaría, AJD (7.6.1788), libro 141, f. 406.

37 ABE, Secretaría, AJD (7.6.1788), libro 141, ff. 406-407.
} 
su continuación, así como poder pasar a Cartagena cuando comenzasen a ceder un poco los calores. Parece que el calor era uno de los problemas que le estaban afectando sobremanera. Entre tanto, según el dictamen de los médicos, seguiría en Valencia llevando adelante lo que pudiese, y accesoriamente las diligencias empezadas para el cumplimiento de los encargos confiados. La Junta aprobó esta disposición, que califica de "tan acertada", encargando a Mena que prefiera el cuidado de su salud, hasta que la recobre y se halle en estado de continuar su viaje, sin ningún riesgo de ella ${ }^{38}$.

La tardanza del correo pone de manifiesto el solapamiento de noticias, pero ahora Mena sí que informa sobre el estado de su salud. Por otro lado, parece intuirse la presión que siente por acudir a Cartagena, habida cuenta de que tenía encargos importantes y específicos de los que ocuparse allí. Transcurridas unas tres semanas, en otro oficio de 5 de julio, Salvador de Mena hace referencia a algunos de los temas de los que se ha ocupado, como son los relacionados con las contratas de municioneros de las factorías de Gandía, Castellón y Villena. La Junta acuerda que se le conteste lo que se estimase conveniente para su instrucción ${ }^{39}$. A ello se le dará respuesta, según lo acordado en las Juntas de 23 y 30 de julio, aprobando que se lleve a efecto la supresión de diversas factorías, como proponía Mena ${ }^{40}$. Sin embargo, los comisionados del Banco en Valencia -Tomás Vague y José Bonelli, que estaban asociados en una compañía mercantil- van a elevar una representación, donde exponen determinados factores en contra de la supresión realizada de la factoría en Villena, mas el Banco confirmará la legalidad de tal supresión y, con ello, la razón que asiste a Mena ${ }^{41}$.

Prosiguen las actuaciones y, a principios de agosto, se da cuenta en la Junta de dos cartas remitidas por Pedro Galavert ${ }^{42}$ y Salvador de Mena, escritas el 26 de julio, acerca de diversos aspectos de la provisión, relacionados con la duda de si interesaba más que continuase el suministro directo de víveres del Ejército en el reino de Valencia o que se subarriende. Se le comunicará a Mena que lo subarriende ${ }^{43}$.

\subsection{Mena suspende la visita por recomendación médica y regresa enfermo a Belmonte}

Desde mediados de junio nada comenta Mena de su salud. Sin embargo, el 5 de agosto comunica, en un oficio al Banco, que tiene casi concluida la visita a Valencia, pero "no permitiéndole el estado de su salud pasar a Alicante y Cartagena, mientras no temple la estación de los calores [...], que ambos parajes son peligrosos y excesivos [...], y estando acordes los médicos, desde que le faltó la calentura y viendo el poco efecto de los baños del mar, en que le convendría salir de Valencia para algún pueblo donde los aires menos húmedos y en don-

38 ABE, Secretaría, AJD (17.6.1788), libro 141, ff. 456-457.

${ }^{39}$ ABE, Secretaría, AJD (10.7.1788), libro 141, ff. 551-554.

40 ABE, Secretaría, AJD (23.7.1788), libro 142, ff. 25v-27 y AJD (30.7.1788), libro 142, ff. $41 \mathrm{v}-42$.

${ }^{41}$ ABE, Secretaría, AJD (20.8.1788), libro 142, ff. 78v-79v.

${ }^{42}$ Comisionado del Banco en Valencia y cuñado de Francisco Cabarrús, quien se había casado en la ciudad del Turia en 1772 con Teresa Galavert, familia asentada en dicha capital que se dedicaba a la banca y a la industria, por ejemplo, una fábrica de jabón (Moreno Fernández, 2014, 35).

${ }^{43}$ ABE, Secretaría, AJD (2.8.1788), libro 142, ff. 55-55v. 
de mayor facilidad pudiere usar del campo [...]”. Por ello, Mena había determinado pasar a su "País" y esperar hasta mediados de septiembre, aguardando mejor tiempo para ir a Cartagena. La Junta aprobó esta resolución, manifestando a Menalio que deseaba consiga su entero restablecimiento, asegurándose bien de él antes de partir para Cartagena ${ }^{44}$.

Luego de llegar a su tierra, Mena remite un oficio el 24 de agosto, por el que da las más expresivas gracias por haber aprobado su determinación de venir a la villa de Belmonte, para "esperar la templanza de los calores" y atender únicamente a su restablecimiento.

La Junta en vista de las circunstancias, consideró que las tareas y fatigas que sobrevendrían a Mena en Cartagena, Andalucía y Extremadura podían perjudicar gravemente su salud en las estaciones próximas de otoño e invierno. Por otra parte, como quedaba ya poco tiempo para evacuar dichas visitas antes de final de año, acordó que las suspendiese y tratase sólo de recobrar enteramente su salud en dicha villa de Belmonte o donde le acomodase por todo el tiempo que necesitare para ello, sobre cuyo punto espera la Junta que Mena no perdonará medio alguno conducente para conseguirlo, y añadiendo prevenir a Ceán para que se restituyese a la Corte ${ }^{45}$. En consecuencia, Mena únicamente estuvo en Valencia, aunque, por los documentos del Banco, conocemos todas las provincias que estaba planificando que visitaría, si bien no pudo realizarlas.

A principio de septiembre, el secretario del Banco dará cuenta de haber recibido tres cartas de Salvador de Mena ${ }^{46}$. Una, fechada el 31 de agosto de 1788 en la villa de Sisan$\mathrm{te}^{47}$, en que informa que, teniendo en cuenta "la proporción que le da la compañía de sus gentes para poder pasar sin la de Juan Agustín de Ceán Bermúdez, cuya asistencia hasta ahora le había sido verdaderamente necesaria para su persona, dejando aparte su exacto desempeño en lo tocante al Banco", Mena había ordenado a Ceán que pasara a la Corte, en este intermedio, por la propia necesidad que tenía de algún desahogo y descanso y ver a su familia, así como disponer algunas cosas necesarias para volver a emprender la visita. Por tanto, queda Mena en Sisante, al cuidado de sus gentes, y da permiso a Ceán Bermúdez para regresar a la Corte para descansar al lado de su familia. Demuestra Mena así su agradecimiento personal y profesional a Ceán ante la Junta directiva del Banco.

Otra carta, con fecha 2 de septiembre, en la que Menalio manifiesta que se conforma en suspender la visita y tratar únicamente de restablecer su salud, según lo acordado por la Junta en 27 de agosto pasado, aunque le sería sensible no sacar de este viaje la instrucción del ramo de Marina, que se le había propuesto, con la inspección ocular del departamento de Cartagena y que, como manifestó, "era la utilidad con que contaba principal y casi únicamente". Lamenta que no había podido todavía ordenar la exposición de lo actuado en la visita de Valencia en los tres ramos de Ejército, Vestuario y Giro, y dice que "el remitir a la Junta la colección de documentos y papeles en que por menor está especificado, sería remitirla una obra informe e insuficiente para el fin que se dirige [...], por lo que se reserva para entregárselos por su mano, informándola al mismo tiempo sobre todo aquello que puede conducir a su gobierno". Entretanto no finalice un completo informe en limpio, para que la Junta se formase algún concepto del estado actual del ramo de provisiones,

\footnotetext{
44 ABE, Secretaría, AJD (11.8.1788), libro 142, ff. 73v-74.

45 ABE, Secretaría, AJD (27.8.1788), libro 142, ff. 102-103.

46 ABE, Secretaría, AJD (6.9.1788), libro 142, ff. 137v-139.

47 Población distante unos $65 \mathrm{~km}$ de Belmonte.
} 
Menalio incluye copia del auto de la visita que dejó a los comisionados Vague y Bonelli a su partida de Valencia.

Con esta carta Mena refleja que para él sigue siendo prioritario el trabajo que ha desarrollado. Mantiene en su cabeza lo que ha hecho y lo que le queda por hacer. Es evidente que, aunque no se encontraba bien de salud, no se hallaba tan mal como para verse impedido de proseguir la visita. Muestra que su objetivo principal en el desarrollo de la visita no era en sí la revisión de los distintos contratos de suministros. Posiblemente, lo considerase como una actualización de la que había realizado Piña un par de años atrás y poco podría aportar en ese punto. Lo que más le atraía, y que no pudo acometer, era la instrucción del ramo de Marina en Cartagena, que debía ser lo novedoso en su visita.

Respecto a remitir los papeles al Banco, que parece que este le propone, dice que no los tiene ordenados y que prefiere entregarlos en mano y explicarlos, lo cual tiene el sentido de que se vea a las claras lo que ha actuado y por qué, en un deseo de hacer constar su trabajo y valía que, de otro modo, quedaría oculto en el amasijo de papeles que pudieran revisarse sin más desde el Banco. Aun así remite una parte resumida de la documentación.

En la tercera carta, fechada el 3 de septiembre, reconoce el mérito y desempeño de Ceán en su encargo. Tiene el objetivo de destacar a Ceán profesionalmente, puesto que el mérito personal y la ayuda que le había prestado ya quedaba manifestada en la primera carta comentada. La Junta quedó satisfecha con los buenos servicios de dicho Ceán Bermúdez y acordó se diesen gracias a Salvador de Mena por el celo y actividad que se reconoce en cuanto ha practicado.

Serían estas las últimas cartas de Menalio al Banco reflejadas en las actas, por lo que desconocemos la evolución de su mortal enfermedad los tres últimos meses de vida, desde principios de septiembre hasta principios de diciembre de 1788.

\subsection{Sustitución del director general de provisiones Mena}

Al no tener constancia, a través de las actas, de nuevas comunicaciones con el Banco desde septiembre de 1788, nos encontramos que el secretario directamente, en la Junta de Dirección del 18 de diciembre, sin más información previa, da cuenta oficialmente del fallecimiento de Salvador María de Mena, director de las provisiones, el 8 del mismo mes, según consta del aviso dado a los directores de Giro por su padre Ignacio de Mena, "cuyo suceso ha sido muy sensible a la Dirección por las recomendables prendas de celo, inteligencia y probidad que acreditó aquel director"48.

Con este simple comentario la Junta recoge el suceso sin que, por otra parte, se explayen mucho sobre la figura de Mena. Posiblemente, el Banco interpretaba que el origen o causa de esta desgracia había sido la visita que se le había encomendado.

Por Miguel de Mena, apoderado de Ignacio de Mena -padre y heredero de Menalio-, se presentó la cuenta de gastos del viaje a Valencia y de la interrumpida visita a las provincias, importando 8.577 reales, y, habiendo recibido por adelantado 15.000 , restaban 6.423 a favor del Banco. La Junta aprueba la citada cuenta y determina se satisficieran a dicho Miguel de Mena, 35.111 reales y 2 maravedís que se debían a Salvador de Mena de su sueldo

48 ABE, Secretaría, AJD (18.12.1788), libro 143, f. 64. 
de 5 meses y 8 días, a razón de 80.000 reales al año, hasta el día de su fallecimiento y rebajando de esta cantidad los expresados 6.423 reales $^{49}$.

Posteriormente al preparar la Junta general de accionistas, la Junta de Dirección, en la propuesta que realiza para el nombramiento de los puestos de directores que faltaban por cubrir, hace constar que "no puede menos la Dirección de renovar su sentimiento por la pérdida de D. Salvador de Mena, arrebatado en la flor de la edad a sus parientes y amigos, y a las esperanzas del Banco y de cuantos le conocían"50.

Para llenar la plaza de director bienal que quedó vacante, por la muerte del director de provisiones Salvador de Mena ${ }^{51}$, se proponía la terna de Miguel Fernández Durán Pinedo y Velasco, Martín de Iriarte y Antonio Junco Pimentel. El contenido del acta será llevado a la $7^{\text {a }}$ Junta General del Banco. Por las actas publicadas de dicha junta, sabemos que en la última sesión, la del 2 de abril de 1789, se procede al nombramiento de los directores que faltan, "renovando su sentimiento por la pérdida de don Salvador de Mena" (BNSC, 1789, 90).

Más adelante la Junta General procede a elegir el sustituto de Mena, como director bienal, no como director de provisiones, ya que este se amortizaba, signo evidente de que el Banco abandonaba el ramo de los avituallamientos militares: "Y habiendo procedido la junta general a votación por escrutinio, salió electo a pluralidad de votos el señor don Miguel Fernández Durán Pinedo de Velloso para sustituir al señor don Salvador de Mena" (BNSC, 1789, 119). Fernández Durán dimitirá de su cargo al poco tiempo (BNSC, 1789, 120).

Meléndez, que andaba por Madrid "trabajándose" el ascenso a la magistratura, pudo oír personalmente los repetidos elogios de "las recomendables prendas de celo, inteligencia y probidad" sobre su difunto amigo Mena, porque estaba presente en la junta general de accionistas, ya que era poseedor de 25 acciones (BNSC, 1789, 9). Otros asistentes fueron Juan Agustín Ceán Bermúdez representando las 200 acciones de "Las parcialidades de los Indios de San Lucas y Santiago de Nueva España"; Melchor Gaspar de Jovellanos, como "superintendente general de la Orden de Alcántara [250 acciones] y por varias parcialidades de Indios de Nueva España" (1143 acciones) (BNSC, 1789, 32). No estuvo presente D. Ignacio de Mena (25 acciones), padre del fallecido Salvador María, pero delegó su voto en el apoderado Juan Antonio Quintana, padre del poeta y político liberal Manuel José, discípulo predilecto de Meléndez (BNSC, 1789, 41).

Finalmente, encontramos que el Banco de San Carlos relaciona directamente la visita que efectuó a Valencia, con la causa de su muerte. Así en las gratificaciones a sus dependientes que se asignan en ese año por el Banco, la Junta de Dirección, refiriéndose a Ceán Bermúdez y a la citada visita, empezada por la ciudad de Valencia, comenta que Menalio y su secretario, en ella "y con motivo de la enfermedad ocurrida a dicho Mena, de que falleció, consumieron 4 meses [finales de mayo-finales de septiembre de 1788]" 52 . Realmente no fue tanto tiempo efectivo sino, más bien, la mitad (principios de junio-principios de agosto de 1788). La enfermedad fue la originada, por tanto, cuando inició el viaje ya comentado. La gratificación a Ceán fue de 4.000 reales. El Banco era consciente de que Mena había muerto prematura y patrióticamente en acto de servicio.

\footnotetext{
49 ABE, Secretaría, AJD (29.12.1788), libro 143, f. 80.

50 ABE, Secretaría, AJD (28.3.1789), libro 143, ff. 246-247v.

51 Puesto que el Banco iba a dejar de aprovisionar al Ejército, se amortizaban las dos direcciones generales de Provisiones, pero se aumentan en dos las direcciones bienales.

52 ABE, Secretaría, AJD (2.5.1789), libro 144, ff. 55-55v.
} 


\section{CONCLUSIONES SOBRE EL "BANQUERO" MENA}

En el Banco ha quedado principalmente la imagen de Menalio como director bienal, y casi oculta su figura de director de provisiones. Deducimos que la razón primordial es que, al no figurar como tal en el resumen de la composición de la Dirección, que se recoge en las Juntas Generales, no se puede tomar el dato directamente de ahí sino que hay que leer el acta correspondiente. De este modo, en la $6^{\mathrm{a}}$ Junta General (febrero de 1788) Mena no era director de provisiones, pues es aquí cuando se le nombra, y en la $7^{\mathrm{a}}$ (marzoabril de 1789) ya había fallecido con lo cual tampoco ya lo era.

El hecho de que llevara a Ceán Bermúdez a la visita deriva de que resultaba la persona idónea. Primero, por haber estado en la visita anterior y, segundo, porque se realizaba en los mismos lugares. Además, a su favor tenía los inmejorables informes dados por Juan de Piña en 1786. Por consiguiente, nada tiene que ver Cabarrús con que fuera a esta visita, ni tampoco era Ceán ya su secretario, puesto que llevaba trabajando en el Banco desde 1783. Ceán demostró su carácter de buen profesional y su humanidad al ocuparse constantemente de Mena durante la enfermedad.

Nuestra impresión personal acerca de su etapa de director de provisiones en Valencia, con la mínima información de que se dispone, es que se lo tomó en serio y tuvo la desgracia de caer enfermo antes de empezarla; aun así puso por delante el trabajo y su profesionalidad. No cabe duda de que en las difíciles condiciones por las que atravesaba el Banco en 1787 era un reto admitir el nombramiento de director de provisiones y él lo asumió. De la visita esperaba obtener un bagaje, en especial en el ramo de Marina, que todavía no se había explorado, como demuestra su especial interés en llegar a Cartagena. Llevó a cabo actuaciones para mejorar la gestión de las provisiones, pero quedó interrumpida su tarea por el agravamiento de su enfermedad.

Este fue el prematuro final de Menalio, reformista convencido, amigo de poetas (no se ha conservado ningún poema propio) y considerado miembro de la Escuela poética salmantina, capitaneada por Meléndez Valdés. Tuvo el consuelo de morir en acto de servicio (la inspección a los suministros militares en Valencia), acompañado por el eficaz y fiel secretario, y futuro entusiasta historiador del arte Agustín Ceán Bermúdez, amigo de Jovellanos y de Goya, gracias a cuyos cuidados pudieron concluir la visita a Valencia.

Hemos tenido el atrevimiento de internarnos en el jardín ajeno de la Historia económica y nos hemos interesado por la enigmática figura del director general de provisiones Salvador María de Mena, exclusivamente por su íntima amistad con Meléndez Valdés y por la huella que encontramos en la obra del poeta extremeño: una carta (16 de marzo de 1782) y dos poemas (la oda V, A Don Salvador de Mena, en un infortunio [Meléndez, 2004, 532-33] y la epístola XVIII, A Menalio, sobre la ambición [Meléndez, 2004, 718-719]. Puesto que adoptó el nombre arcádico de Menalio, se supone que asistió a las reuniones poéticas que en el periodo 1775-1779 se celebraban en la celda del prior de los agustinos calzados Diego Tadeo González. El poeta extremeño rindió su reconocimiento a esa amistad, enraizada en semejanzas de carácter, de formación jurídica y de ideología ilustrada, lo que ha permitido que el bueno de Menalio pase a la historia literaria como un miembro de la Escuela poética salmantina de la segunda mitad del siglo XVIII, sin haber escrito un solo verso, que sepamos. Es una manera indirecta de rememorar las efemérides del bicentenario del fallecimiento de su amigo Meléndez Valdés (Montpellier, 24 de mayo de 1817). 


\section{BIBLIOGRAFÍA Y FUENTES} ARCHIVOS Y FUENTES

ABE= Archivo del Banco de España (Madrid): Secretaría, caja 1072; Actas de la Junta de Dirección (AJD) libro 156; Actas reservadas (AR), fol. 130.

AGS= Archivo General de Simancas; SSH (Secretaría y Superintendencia de Hacienda), leg. 647. AUSA = Archivo de la Universidad de Salamanca: Libro de Claustros 242 (años 1779-1782); Libro de Claustros 243; Libros de Claustros 239; leg. 3871, exp. 27 (Expediente académico de Salvador María de Mena); Libro 555 (Libro de registros de exámenes de estudiantes para ingresar en Facultad Mayor, años 1769-1819).

BNSC = Banco Nacional de San Carlos; RJGA= Reglamento de la Junta de Gobierno, año 1789 (1789); RCE= Real Cédula de erección del Banco Nacional de San Carlos, de 2 de Junio de 1782; RJG= Reglamento de la Junta de Gobierno (1789).

\section{BIBLIOGRAFÍA}

ANDÚJAR ORTEGA, L. (1995): Belmonte, cuna de Fray Luis de León. Su Colegiata, Mota del Cuervo, 97-103.

ASTORGANO ABAJO, A. (2002): "Juan Meléndez Valdés, opositor a la cátedra de Prima de Letras Humanas", Dieciocho, 25-1, 75-105.

ASTORGANO ABAJO, A. (2007): Don Juan Meléndez Valdés, el ilustrado, Badajoz, Diputación Provincial, $749 \mathrm{p}$.

ASTORGANO ABAJO, A. (2012a): "Las aventuras del canónigo González de Candamo, íntimo amigo de Meléndez Valdés, en Nueva España (1787-1804)", Revista de Estudios Extremeños, LXVIII-III, 1257-1322.

ASTORGANO ABAJO, A. (2012b): "El Colegio Menor Universitario Nuestra Señora de la Vega de Salamanca durante la Ilustración (1771-1808)", en: Rodríguez-San Pedro, L. E. y Polo Rodríguez, J. L. (Eds.), Imagen, contextos morfológicos y universidades, Miscelánea Alfonso IX, Salamanca, Centro de Historia Universitaria Alfonso IX, 349-397.

ASTORGANO ABAJO, A. (2016a): "Poesía y jansenismo en el convento de los agustinos calzados de Salamanca en tiempos de Meléndez Valdés”, Revista de Estudios Extremeños, LXXII-I, 147-208.

ASTORGANO ABAJO, A. (2016b): "Biografía de Salvador María de Mena, el abogado de la Escuela poética salmantina (1754-1788)", Boletín de la Real Academia de Extremadura n. ${ }^{\circ}$ XXIV, 101-172.

ASTORGANO ABAJO, A. (2016c): "Salvador María de Mena (Menalio) y la Escuela poética salmantina (1754-1788)", XIV reunión científica de la Fundación de Historia Moderna, Zaragoza, junio de 2016 (en prensa).

BANCO NACIONAL DE SAN CARLOS (BNSC, 1788b): Accionistas del Banco nacional de San Carlos, ... en el día 24 de Febrero de 1788, s/l, s/a, ejemplar en Biblioteca Nacional de Madrid, sig. VC/103/12.

BANCO NACIONAL DE SAN CARLOS (BNSC, 1786): $4^{a}$ Junta General del Banco Nacional de San Carlos ... en 29 de Diciembre 1785, Imprenta de la Viuda de Ibarra, Hijos y Compañía, Madrid, 1786.

BANCO NACIONAL DE SAN CARLOS (BNSC, 1787): 5. ${ }^{a}$ Junta General del Banco Nacional de San Carlos celebrada en ... 18 de Diciembre 1786, Imprenta de la Viuda de Ibarra, Hijos y Compañía, Madrid, 1787.

BANCO NACIONAL DE SAN CARLOS (BNSC, 1788a): 6. ${ }^{a}$ Junta General del Banco Nacional de San Carlos ... en 24 de Febrero 1788, Madrid, Imprenta de la Viuda de Ibarra, Hijos y Compañía, 1788. 
BANCO NACIONAL DE SAN CARLOS (BNSC, 1789): 7. ${ }^{a}$ Junta General del Banco Nacional de San Carlos ... en 29, 30 y 31 de Marzo, 1 y 2 de Abril de 1789, Madrid, Imprenta de la Viuda de Ibarra, 1789.

Diario curioso, erudito, económico y comercial, tomo II (octubre, noviembre y diciembre de 1786), Madrid, Imprenta de Manuel González. Lista de suscriptores en pp. 1-8.

GONZÁLEZ ENCISO, A. (2012): "La renovación del asiento de transporte de municiones y armas en 1793 y el protagonismo de una familia navarra", Memoria y Civilización, 15, 51-69.

GARCÍA HOURCADE, J. J. (2007): "Un episodio mal conocido de la vida académica murciana: la academia eclesiástica de San Ginés (1742-1768)", Murgetana,116, 101-114.

MELÉNDEZ VALDÉS, J. (2004): Obras Completas, Madrid, Cátedra, 1593 p. Edición de A. Astorgano.

MORENO FERNÁNDEZ, R. (2009): El personal del Banco de España: desde su origen en el siglo XVIII hasta fin del siglo XIX, vol. 1: Banco de San Carlos, Madrid, Banco de España, Estudios de Historia Económica, 108 p.

MORENO FERNÁNDEZ, R. (2014): Las demandas contra la actuación gestora de Cabarrús y demás directores del Banco Nacional de San Carlos (1782-1797), Madrid, Banco de España, Estudios de Historia Económica, 198 p.

SOLBES FERRI, S. (2015): "Gasto militar y agentes privados. La provisión de uniformes para el ejército español en el siglo XVIII", Tiempos Modernos, Revista Electrónica, vol. 8, no 30.

TEDDE DE LORCA, P. (1988): El Banco de San Carlos (1782-1829), Madrid, Alianza Editorial, $395 \mathrm{p}$.

TORRES SÁNCHEZ, R. (2002a): “Cuando las reglas del juego cambian. Mercados y privilegio en el abastecimiento del ejército español en el siglo XVIII", Revista de Historia Moderna, 20, 487-511.

TORRES SÁNCHEZ, R. (2002b): "El gran negocio de la época, la provisión de víveres al ejército por Francisco Mendinueta (1744-1763)", en Aquerreta, S. (ed.): Francisco Mendinueta: Finanzas y mecenazgo en la España del siglo XVIII, Pamplona, Universidad de Navarra, 101-134.

TORRES SÁNCHEZ, R. (2003): "Las dificultades de ser financiero extranjero en la España de Carlos III”, en María Begoña Villar García, M ${ }^{a}$ B. y Pilar Pezzi Cristóbal, P. (dirs.), I Coloquio Internacional "Los extranjeros en la España Moderna", Málaga, Ministerio de Ciencia e Innovación 2003, tomo II, 771-780.

TORRES SÁNCHEZ, R. (2008): "Financiers et politiques. Francisco Montes et François Cabarrus (1770-1790)", en Dubet, A. (ed.): Administrer les finances royales dans la monarchie espagnole (XVIe - XIXe siècles), Rennes, Presses universitaires de Rennes, 103-120.

TORRES SÁNCHEZ, R. (2012): "Los Cinco Gremios Mayores y la provisión de víveres al ejército español en el siglo XVIII", Studia Histórica. Edad Moderna, n 34, 407-432.

TORRES SÁNCHEZ, R. (2013): “Administración o asiento: la política estatal de suministros militares en la monarquía española del siglo XVIII", Studia historica. Historia moderna, 35, 159-199.

ZYLBERBERG, M. (2004): "Des affaires à l'administration: un échec de François Cabarrus", en Vincent, B. y Dedieu, J.-P. (coords.): L'Espagne, l'Etat, les Lumières: mélanges en l'honneur de Didier Ozanam, Madrid, Casa de Velázquez, 109-119. 